\title{
DETERM INAÇÃO DE AUTOANTICORPOS PARA ANTÍGENOS DA MIELINA NO SORO DE PACIENTES HLA - DQB1*0602 COM ESCLEROSE MÚLTIPLA
}

\author{
Adriana Carvalho', Gabriele Sant'anna², Cláudio Cirne Santos ${ }^{3}$, \\ Izabel Palmer Frugulhetti ${ }^{4}$, Soniza Alves Leon ${ }^{5}$, Thereza Quírico-Santos ${ }^{6}$
}

\begin{abstract}
RESUMO - Esclerose múltipla (EM) é doença inflamatória desmielinizante do sistema nervoso central (SNC) de natureza autoimune, mediada por linfócitos Th1. A produção de autoanticorpos séricos para proteína básica da mielina (MBP), proteolipídeo PLP e sequência da glicoproteína de oligodendrócito MOG 92-106, foi determinada em 54 indivíduos saudáveis e 26 pacientes com EM expressando ou não 0 alelo de suscetibilidade HLA-DQB1*0602. Independentemente da expressão do alelo DQB1*0602, todos os pacientes apresentaram produção marcante $(p<0,0001)$ de autoanticorpos isotipo IgG para MBP e MOG 92-106, e do isotipo IgA para PLP e MOG 92-106. Os resultados sugerem que outros alelos HLA da classe II exerçam influência na suscetibilidade à EM e no reconhecimento imunológico dos antígenos encefalitogênicos, determinando o padrão de resposta autoimune e contribuindo na manutenção e/ou controle da inflamação no SNC.
\end{abstract}

PALAVRAS-CHAVE: esclerose múltipla, desmielinização, autoimunidade, antígenos da mielina, HLA DQB1*0602.

\section{Determination of autoantibody for myelin antigens in the serum of patients HLA - DQB1*0602 with multiple sclerosis}

\begin{abstract}
Multiple sclerosis (MS) is a chronic inflammatory demyelinating disease of the human central nervous system (CNS) mediated by autoimmune Th1 lymphocytes. We determined the serum levels of autoantibodies for myelin basic protein (MBP), proteolipid (PLP) and myelin oligodendrocyte glycoprotein sequence MOG 92-106 in a group of 54 healthy individuals and 26 MS patients expressing or not HLA DQB1*0602. Regardless expression of the susceptibility alelle DQB1*0602, MS patients presented marked $(p<0.0001) \lg G$ antibody production for MBP and MOG92-106. Yet, significant $(p<0.0001) \lg A$ antibody levels were mainly observed for PLP and MOG antigens. Our results suggest that other HLA class II alleles may be conferring susceptibility to MS in this population and influencing the pattern of immune recognition of encephalitogen antigens. Furthermore, distinct IgG and/or IgA autoantibody production may be contributing to the control or maintenance of the CNS inflammatory reaction.
\end{abstract}

KEY WORDS: multiple sclerosis, demyelination, myelin antigens, autoimmunity, HLA, DQB1*0602.

Esclerose múltipla (EM) é doença crônica inflamatória e desmielinizante do sistema nervoso central (SNC) de natureza autoimune, que apresenta intenso infiltrado perivenular de células mononucleares, perda de oligodendrócitos e lesão axonal ${ }^{1-4}$. Estudos epidemiológicos mostram distribuição heterogênea da doença pelo mundo e incidência em $0,1 \%$ da população nos países de clima temperado ${ }^{2}$. Nos países de clima tropical como o Brasil, a doença era considerada rara, porém dados recentes ${ }^{3}$ relatam incidên- cia elevada da EM em indivíduos brancos e também nos de etnia negra (afro-brasileiros). EM é considerada doença de etiologia multifatorial, em que a existência de predisposição genética aliada a fatores externos seria determinante no desencadeamento dos eventos imunológicos relacionados com o processo inflamatório e desmielinizante no $\mathrm{SNC}^{4}$. A susceptibilidade genética a EM é influenciada por alelos da classe Il do complexo principal de histocompatibilidade (HLA). Esses alelos são muito importantes no

\footnotetext{
Departamento de Biologia Celular \& Molecular, Instituto de Biologia, Universidade Federal Fluminense (UFF), Niterói, Rio de Janeiro RJ Brasil. Hospital Universitário Clementino Fraga Filho, Universidade Federal do Rio de Janeiro (UFRJ), Rio de Janeiro RJ, Brasil: ${ }^{1}$ Mestre em Neuroimunologia, UFF; ' ${ }^{2}$ Acadêmica de Ciências Biológicas, UFF; ${ }^{3}$ Mestre em Neuroimunologia, UFF; ${ }^{4}$ Professora Adjunta, UFF; ${ }^{5}$ Professora Adjunta, Universidade do Rio de Janeiro e Médica Neurologista - UFR]; ${ }^{6}$ Professora Titular, UFF. Agência Financiadora: CNPq, CAPES.
}

Recebido 26 Fevereiro 2003, recebido na forma final 16 Maio 2003. Aceito 24 Julho 2003.

Dra. Thereza Quírico-Santos - Laboratório de Patologia Celular, Instituto de Biologia - Universidade Federal Fluminense - Campus do Valonguinho - 24210-030 Niterói RJ - Brasil. E-mail:tquirico@ vm.uff.br 
reconhecimento de epítopos encefalitogênicos da mielina, participando na formação do repertório de células T e no padrão da reatividade imunológica. Em sua maioria, os genes do complexo HLA são altamente polimórficos e as variantes de seus alelos estão implicadas na susceptibilidade e/ou proteção a várias doenças autoimunes ${ }^{5}$. Tem sido descrita forte associação dos alelos DQB1*0602, DQA1*0102 e DRB1*1501 que compõem o haplótipo DR2 no desenvolvimento da EM na população caucasiana ${ }^{6,7}$. Contudo, o alelo DQB1*0602 parece conferir susceptibilidade à doença, mesmo na ausência da expressão dos alelos DQA1*0102, DRB1*1501².
A extensa reação inflamatória com predomínio de linfócitos $\mathrm{CD}^{+}{ }^{+} \mathrm{TCR} \alpha \beta$ com marcante produção local de citocinas e quimiocinas geralmente precede ou acompanha a formação da placa de desmielinização e a citotoxidade de oligodendrócitos no $\mathrm{SNC}^{1,2,4}$. Contudo, a deposição de imunoglobulinas e componentes da ativação do sistema complemento próximo da lesão inflamatória sugere participação importante dos linfócitos B na fisiopatologia da lesão no SNC9,10. A proteína básica da mielina (MBP), o proteolipídeo (PLP) e a sequência MOG 92-106 da glicoproteína associada ao oligodendrócito são considerados os principais componentes encefalitogê-

Tabela 1. Características gerais dos pacientes.

\begin{tabular}{|c|c|c|c|c|c|c|c|}
\hline Paciente & Idade & $\begin{array}{c}\text { Idade } \\
1^{\circ} \text { surto }\end{array}$ & Etnia & Sexo & EDSS & Forma & $\begin{array}{c}\text { Duração } \\
\text { (anos) }\end{array}$ \\
\hline EM 1 & 21 & 21 & $\mathrm{AF}$ & $\mathrm{F}$ & 5,0 & SR & $<1$ \\
\hline EM 2 & 42 & 40 & $C A$ & $\mathrm{~F}$ & 2,5 & $S R$ & 2 \\
\hline EM 3 & 39 & 34 & $C A$ & $\mathrm{~F}$ & 2.0 & $S R$ & 5 \\
\hline EM 4 & 15 & 15 & $C A$ & $\mathrm{~F}$ & 3.0 & $\mathrm{SR}$ & 1 \\
\hline EM 5 & 48 & 46 & $C A$ & $M$ & 2.5 & $S R$ & 2 \\
\hline EM 6 & 44 & 43 & $A F$ & $M$ & 2.0 & $S R$ & 1 \\
\hline EM 7 & 18 & 18 & CA & $M$ & 3.0 & $S R$ & $<1$ \\
\hline EM 8 & 33 & 24 & $\mathrm{CA}$ & $\mathrm{F}$ & 3.0 & $S R$ & 9 \\
\hline EM 9 & 38 & 28 & CA & $M$ & 1.0 & SR & 10 \\
\hline EM 10 & 51 & 28 & CA & $\mathrm{F}$ & 7.5 & PP & 23 \\
\hline EM 11 & 23 & 19 & $A F$ & $\mathrm{~F}$ & 7.5 & $S R$ & 4 \\
\hline EM 12 & 53 & 52 & $A F$ & $\mathrm{~F}$ & 4.5 & PP & 1 \\
\hline EM 13 & 44 & 25 & $\mathrm{CA}$ & $\mathrm{F}$ & 5.0 & $\mathrm{SR}$ & 19 \\
\hline EM 14 & 51 & 50 & $\mathrm{CA}$ & $\mathrm{F}$ & 3.5 & PP & 1 \\
\hline EM 15 & 16 & 8 & CA & $\mathrm{F}$ & 7.0 & SR & 8 \\
\hline EM 16 & 28 & 21 & $\mathrm{CA}$ & $\mathrm{F}$ & 7.5 & $\mathrm{SR}$ & 7 \\
\hline EM 17 & 40 & 30 & $C A$ & $\mathrm{~F}$ & 1.0 & SR & 10 \\
\hline EM 18 & 48 & 35 & $\mathrm{AF}$ & $\mathrm{F}$ & 7.5 & SR & 13 \\
\hline EM 19 & 54 & 31 & $A F$ & $\mathrm{~F}$ & 3.0 & PP & 23 \\
\hline EM 20 & 46 & 40 & $C A$ & $\mathrm{~F}$ & 5.0 & SR & 6 \\
\hline EM 21 & 47 & 45 & $\mathrm{AF}$ & $\mathrm{F}$ & 3.0 & SR & 2 \\
\hline EM 22 & 41 & 41 & $\mathrm{AF}$ & $\mathrm{F}$ & 2.0 & SR & $<1$ \\
\hline EM 23 & 48 & 41 & $C A$ & $\mathrm{~F}$ & 7.5 & PS & 7 \\
\hline EM 24 & 37 & 21 & $\mathrm{CA}$ & $\mathrm{F}$ & 3.5 & SR & 16 \\
\hline EM 25 & 37 & 36 & $\mathrm{AF}$ & $\mathrm{F}$ & 3.5 & SR & 1 \\
\hline EM 26 & 35 & 34 & $\mathrm{AF}$ & $\mathrm{F}$ & 2.0 & SR & 1 \\
\hline
\end{tabular}

$\mathrm{SR}$, forma surto-remissão; $\mathrm{PP}$, forma progressiva primária; $\mathrm{PS}$, forma progressiva secundária; $\mathrm{CA}$, caucasóide; $\mathrm{AF}$, afro-brasileiro. 
nicos da mielina do SNC implicados na patogenia da EM e na indução da encefalomielite autoimune experimental - EAE, modelo da esclerose múltipla em diferentes espécies de vertebrados ${ }^{9,11-13}$.

Este estudo teve como objetivo analisar, numa população de pacientes com EM da cidade do Rio de Janeiro expressando o alelo de suscetibilidade HLA - DQB1*0602, a produção de autoanticorpos dos isotipos Ig $\mathrm{G}$ e lgA relacionados com ativação da resposta imune humoral influenciada, respectivamente, por linfócitos do tipo Th1 e Th2, para antígenos imunodominantes da mielina com localização e características bioquímicas distintas.

\section{MÉTODO}

Ética - A comissão de ética da Universidade Federal do Rio de Janeiro (UFRI) aprovou a execução deste estudo que integra o projeto de pesquisa com registro 1265/2000 do Conselho Nacional de Ética em Pesquisa (CONEP). Pacientes e integrantes do grupo controle forneceram seu consentimento por escrito para participar do estudo.

Grupos de estudo - Foram incluídos 26 pacientes com EM clinicamente definida ${ }^{14} \mathrm{em}$ acompanhamento ambulatorial no Setor de Doenças Desmielinizantes Primárias do Sistema Nervoso Central do Serviço de Neurologia do Hospital Universitário Clementino Fraga Filho (HUCFF) da Universidade Federal do Rio de Janeiro (UFRI). Todos os pacientes foram submetidos a exames complementares de tomografia computadorizada e ressonância magnética do cérebro e medula espinhal. No momento da execução do estudo, os pacientes não apresentavam sinais clínicos e/ou laboratoriais de processo infeccioso em atividade.

A maioria (85\%) dos pacientes incluídos no estudo (Tabela 1) era do sexo feminino na faixa etária de 16 a 54 anos (média 35 anos). A média de idade relatada referente ao primeiro surto era de 30 anos (variação 8 a 52 anos). Segundo a etnia, 16 pacientes EM (62\%) eram indivíduos brancos de origem caucasiana (CA) e 10 (38\%) negros, considerados como afro-brasileiros (AF). Neste grupo foram incluídos os descendentes africanos e aqueles advindos da miscigenação com outras etnias. Quanto à evolução clínica, 21 pacientes apresentavam a forma surto-remissiva (SR), 4 a forma progressiva-primária (PP) e somente 1 a forma progressiva-secundária (PS).

A classificação dos pacientes segundo o grau de incapacidade funcional (EDSS) foi baseada na escala de Kurtzke ${ }^{15}$. Após avaliação, 15 pacientes (58\%) foram classificados nos níveis mais baixos $(0$ - 3,0) enquanto $5(19 \%)$ apresentavam EDSS variando de 3,5 a 6,5 e os pacientes mais graves ( $23 \%$ ), foram considerados com grau de incapacitação $\geq 7,0$. Cinco pacientes apresentavam a doença há dez ou mais anos; porém destes, somente o paciente EM17 preencheu os critérios de diagnóstico definidos para a forma benigna da $\mathrm{EM}^{16}$.
Como grupo controle, foram incluídos 54 indivíduos clinicamente saudáveis sem história prévia de doença neurológica e/ou processo inflamatório em atividade. O grupo controle era constituído de 35 indivíduos do sexo feminino (65\%) e 19 do masculino (35\%) com idade variando entre 17 e 58 anos (média 38 anos); quanto à etnia, 9 (17\%) eram negros e 45 brancos (83\%).

Amostras - Para determinação dos níveis de autoanticorpos, o sangue periférico obtido por punção venosa foi coletado em tubo estéril sem anticoagulante. $\mathrm{O}$ soro foi inativado a $56^{\circ} \mathrm{C}$ por $30 \mathrm{~min}$, centrifugado a $200 \mathrm{xg}$ por $10 \mathrm{~min}$ a $25^{\circ} \mathrm{C}$ e somente amostras livres de hemólise foram estocadas em alíquotas de $200 \mu \mathrm{l} \mathrm{a}-20^{\circ} \mathrm{C}$ até o momento do uso.

Antígenos - Proteína básica da mielina (MBP) de cérebro bovino (Sigma Chem. Co; USA), apresentando grau de pureza $>95 \%$, foi aliquotada na concentração $1 \mathrm{mg} /$ $\mathrm{mL}$ e estocada a $-20^{\circ} \mathrm{C}$. Proteolipídeo PLP foi obtido de cérebro de rato Lewis pelo método de partição Folch $\mathrm{Pi}^{17,18}$ utilizando mistura de solvente orgânico (clorofór-
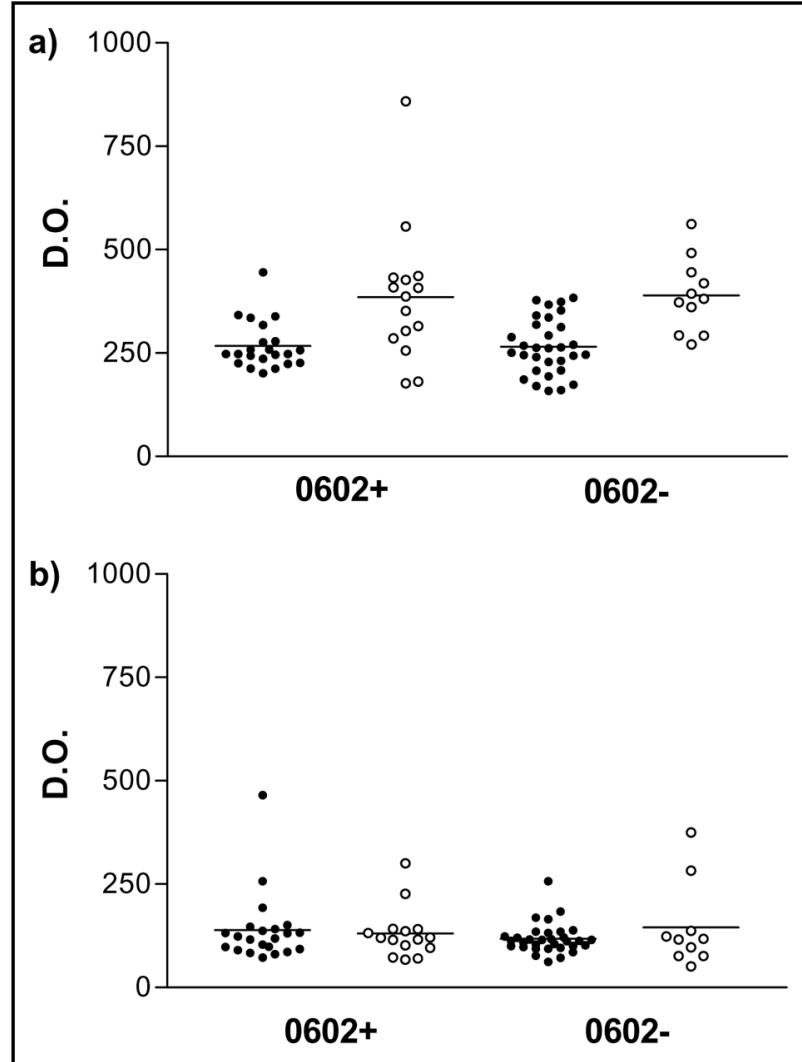

Fig 1. Produção de anticorpos IgG e IgA para MBP. Pacientes EM $(n=26)$ símbolos preenchidos e controle $(n=54)$ símbolos não preenchidos. Determinação de IgG (a) e IgA (b) para molécula nativa da MBP por ELISA. Análise estatística teste $T$ não paramétrico realizada pelo GraphPad Prism, indicou como significativo $o$ aumento de $\lg G(p<0,001)$. 
mio-metanol) e purificação por cromatografia em coluna Sephadex LH-20, obtendo cerca de $95 \%$ de pureza. O material liofilizado foi aliquotado e estocado na concentração de $1 \mathrm{mg} / \mathrm{mL}$ a $-20^{\circ} \mathrm{C}$. A sequência MOG 92-106 (DEGGYTCFFRDHSYQ) com atividade encefalitogênica ${ }^{12}$ foi sintetizada no Laboratório de Bioquímica de Proteínas e Peptídeos do Departamento de Bioquímica e Biologia Molecular da FIOCRUZ, RJ. O peptídeo, apresentando grau de pureza $>95 \%$ confirmado após cromatografia HPLC de fase reversa, foi ressuspenso $(1 \mathrm{mg} / \mathrm{mL})$ emágua destilada e estocado a $-20^{\circ} \mathrm{C}$ em alíquotas de $200 \mu \mathrm{L}$.

Enzima imunoensaio (ELISA) - Os experimentos foram realizados em placas de 96 poços (Corning, USA), recobertas com $50 \mu \mathrm{L}$ dos diferentes antígenos na concentração de $10 \mu \mathrm{g} / \mathrm{mL}$ em tampão PBS pH 8,0. Como antígeno não relacionado, foi utilizada caseína numa concentração de $10 \mu \mathrm{g} / \mathrm{mL}$. As amostras de soro foram diluídas 1:100 em PBS contendo gelatina e 1\% de Tween 20 (Sigma Chem. Co., USA). Para determinação dos autoanticorpos isotipos IgG elgA, foram utilizados os anticorpos anti-lgG e anti-IgA humana produzidos em cabra e os anticorpos conju-

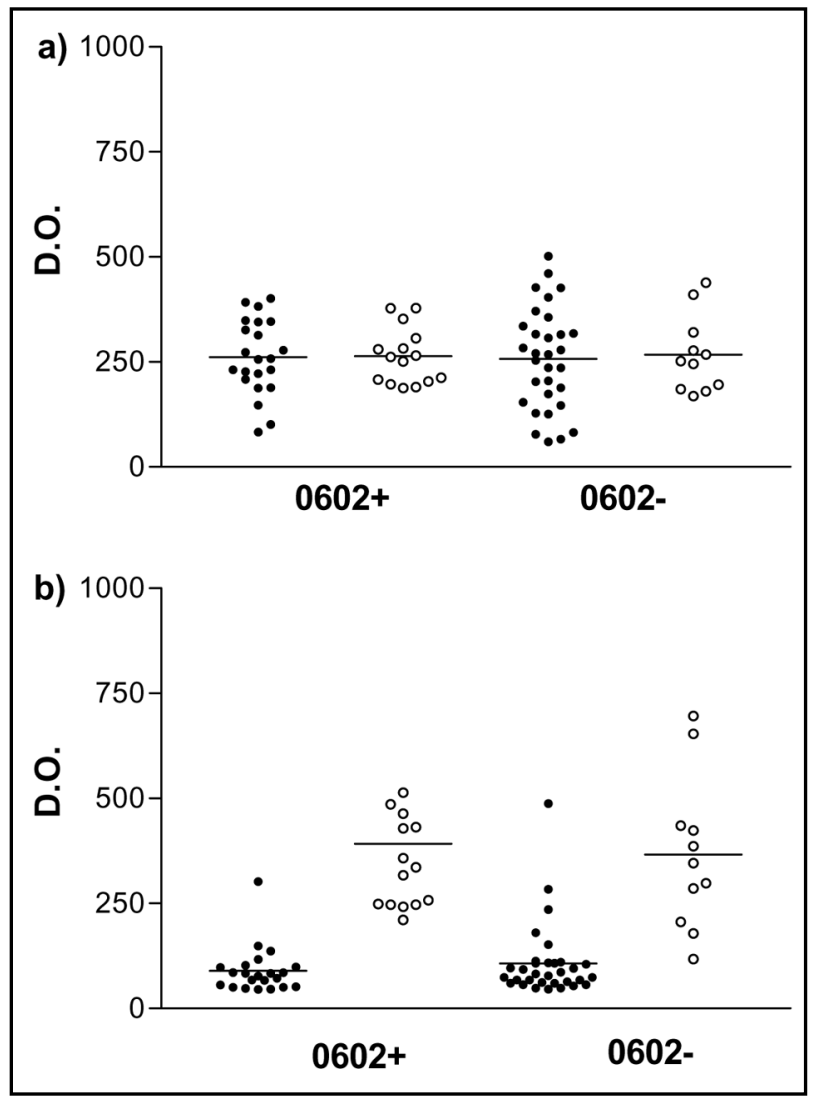

Fig 2. Produção de anticorpos IgG e IgA para PLP. Pacientes EM (n = 26) símbolos preenchidos e controle $(n=54)$ símbolos não preenchidos. Determinação de IgG (a) e IgA (b) para molécula nativa do PLP por ELISA. Análise estatística, teste T não paramétrico realizada pelo GraphPad Prism, indicou como significativo $o$ aumento de $\lg A(p<0,001)$. gados a peroxidase anti-lgG e anti-IgA humana produzidos em cabra (Southern Biotechnology Associates, USA). Para obtenção da curva padrão foram utilizadas imunoglobulinas IgG e IgA humanas purificadas (Caltag Laboratories CA, USA). A reação enzimática desenvolveu-se após adição dos cromógenos TMB (tetra metil di-hidrocloreto de benzidina, Sigma, USA) contendo $\mathrm{H}_{2} \mathrm{O}_{2}$ (Merck, Brasil) em tampão citrato $\mathrm{pH} 4,0$ ou de OPD (orto-fenileno diamino, Sigma, USA) contendo $\mathrm{H}_{2} \mathrm{O}_{2}$ em tampão citrato $\mathrm{pH} 5$,6. Todos os ensaios foram feitos em triplicata e os valores (D.O) obtidos em espectrofotômetro (450 nm ou $492 \mathrm{~nm}$ ).

Análise genômica do alelo HLA-DQB1*0602 - A extração do DNA genômico foi feita a partir de amostras de sangue venoso. As proteínas foram extraídas pelo método de precipitação salina, utilizando $270 \mu \mathrm{L}$ de $\mathrm{NaCl} 4 \mathrm{mM}$ e o DNA precipitado em etanol absoluto. A integridade do DNA foi verificada em gel de agarose $0,8 \%$ e a pureza em espectrometria $(280 \mathrm{~nm})$, considerando-se que uma unidade da D.O corresponde a $50 \mu \mathrm{g} / \mathrm{mL}^{\text {de }} \mathrm{DNA}^{19}$. A técnica de PCR (reação de polimerização em cadeia) para amplificação do fragmento específico de DNA referente ao
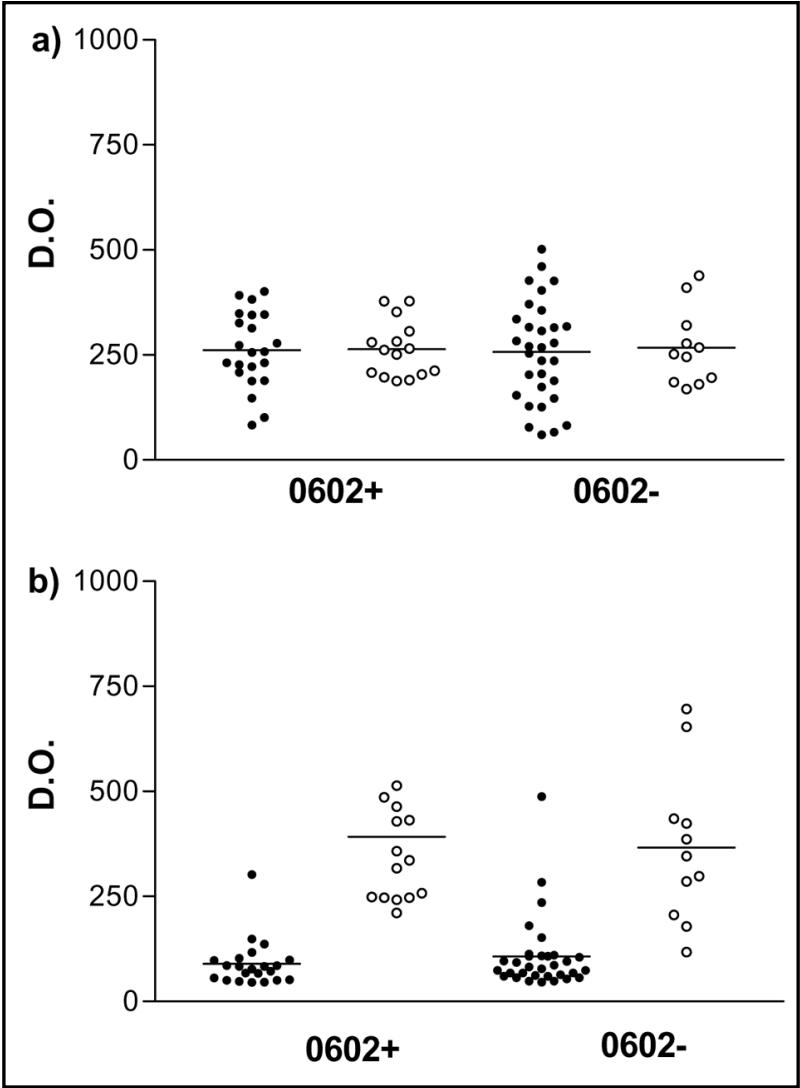

Fig 3. Produção de anticorpos IgG e IgA para MOG. Pacientes EM $(n=26)$ símbolos preenchidos e controle $(n=54)$ simbolos não preenchidos. Determinação de IgG para sequência M OG 92-106 por ELISA. Análise estatística, teste T não paramétrico, realizada pelo GraphPad Prism indicou produção aumentada no grupo EM, $p<0,0001$. 
alelo DQB1*0602 foi realizada utilizando a sequência $5^{\prime}$ $\rightarrow$ 3' (CCG AGG ATT TCG TGT ACC AG) de pares de oligonucleotídeos ${ }^{20}$ obtidos da BRL-Lfe Technologies (São Paulo, Brasil). A análise do produto amplificado foi realizada em gel de agarose a 2,0\%.

Análise estatística - Os dados foram analisados pelo teste Tnão paramétrico, utilizando o programa GraphPad Prism (USA). Somente valores de $p<0,05$ foram considerados com significância estatística.

\section{RESULTADOS}

Expressão do alelo de suscetibilidade

entre os grupos

A análise genômica para determinar a frequência da expressão do alelo HLA da classe II DQB1*0602 mostrou perfil semelhante entre os grupos, sendo $58 \%$ dos pacientes EM e $40 \%$ dos indivíduos do grupo controle positivos para o alelo DQB1*0602.

Determinação dos níveis de $\lg \mathrm{G}$ e $\lg \mathrm{A}$ para MBP, PLP e sequência MOG 92-106

Independentemente da expressão do alelo DQB1*0602, todos os pacientes EM apresentaram (Fig 1a), em relação ao grupo controle de indivíduos sadios, aumento significativo $(p<0,0001)$ na produção de autoanticorpo isotipo lgG para molécula nativa da MBP. A produção de autoanticorpo do isotipo IgA para MBP (Fig 1b) foi semelhante entre pacientes EM e grupo controle, independentemente da expressão $(p=0,74)$ ou não $(p=0,20)$ do alelo DQB1*0602. Contudo, não foi observada diferença significativa nos níveis desse autoanticopo (IgG) entre os pacientes DQB1 $* 0602$ positivos $(385,7 \pm 42,9)$ e DQB1*0602 negativos $(389,4 \pm 26,7)$.

Também não se observou diferença significativa (Fig 2a) nos níveis de autoanticorpo IgG para a molécula nativa do proteolipídeo PLP entre as populações EM expressando ou não o alelo DQB1*0602 e o grupo controle $(p>0,8)$. Em contraste, foi observado em relação ao grupo controle (Fig 2b), aumento significativo ( $p<0,0001)$ na produção de autoanticorpo isotipo IgA para o proteolipídeo PLP. Todos os pacientes EM, independentemente da expressão do alelo DQB1*0602, apresentaram níveis de lgA para esseantígeno acima da média do grupo controle.

A maioria dos pacientes EM apresentou (Fig 3a), em relação ao grupo controle, aumento marcante $(p<0,0001)$ na produção de autoanticorpo isotipo IgG para a sequência encefalitogênica MOG92-106, embora não sendo evidente diferença significativa nos níveis desse autoanticorpo entre os pacientes positivos $(550,4 \pm 46,5)$ e negativos $(615,0 \pm 99,2)$ para o alelo $\mathrm{DQB1} * 0602$.
Diferença ainda mais acentuada (Fig 3b) foi observada na produção de autoanticorpo isotipo IgA para sequência MOG92-106 $(p<0,0001)$. Os pacientes expressando $(714,7 \pm 94,6)$ ou não $(859,8 \pm 128,8)$ o alelo DQB1*0602 apresentaram níveis de lgA acima da média do grupo controle.

\section{DISCUSSÃO}

A etiopatogenia da EM ainda é desconhecida embora um distúrbio ou processo infeccioso sistêmico contribua para o desencadeamento de inflamação recorrente de natureza autoimune com lesões desmielinizantes no SNC1,2,4,10. A inflamação em diferentes regiões do cérebro e a heterogeneidade das manifestações clínicas nos pacientes EM parece ser influenciada pela especificidade do reconhecimento antigênico dos linfócitos T ativados que migram para o SNC e também por mecanismos efetores dependentes de autoanticorpos ${ }^{1,10,21}$. Outro aspecto importante da participação dos linfócitos B na desmielinização refere-se à sua capacidade de funcionar como célula acessória na apresentação de antígenos solúveis durante a resposta imune inicial. Estudos realizados no modelo da EAE ${ }^{22,23}$ indicam que anticorpos contra proteínas da superfície da bainha de mielina (ex. PLP, MOG) causam citotoxidade de oligodendrócitos e contribuem para o desenvolvimento e manutenção da desmielinização em roedores e primatas. Inclusive, experimentos in vivo de depleção de células B com anti-IgM e também no modelo de camundongo nocaute foram capazes de proteger animais suscetíveis da desmielinização experimental induzida por $\mathrm{MOG}^{10}$.

Neste estudo analisamos no soro de pacientes com EM, a produção de autoanticorpos dos isotipos IgG e IgA para moléculas nativas (PLP, MBP) bastante conservadas entre as espécies animais e a sequência de aminoácidos MOG 92-106 (DEGGYTCFFRDHSYQ) associados com desmielinização nos humanos e/ou modelos experimentais ${ }^{11,13,25}$. Os pacientes EM apresentaram, em relação aos indivíduos saudáveis, produção acentuada ( $p<0,0001)$ de autoanticorpos IgG para MBP, sugerindo papel importante da proteína nativa MBP como antígeno indutor da resposta imune do tipo Th1. Em contraste, a marcante produção de autoanticorpo de isotipo IgA sugere que a porção lipídica do proteolipídeo PLP, funcionando como hapteno, favoreça o reconhecimento imunológico pelos linfócitos B e influencie a ativação de linfócitos produtores de citocinas reguladoras (IL-4, TGF $\beta$ ).

A expressão de MOG nos estágios tardios da mielinização e a sua localização mais externa na bainha 
de mielina torna esse antígeno encefalitogênico indutor de potente resposta imune mediada por anticorpo e componentes do sistema complemento ${ }^{12}$. Vale ressaltar que anticorpos contra a sequência MOG92-106 causam desmielinização in vitro em culturas mielinizadas e também in vivo em modelos experimentais da $\mathrm{EAE}^{24,25}$. Recentemente, vários grupos sugerem participação direta desses autoanticorpos na manutenção da resposta inflamatória no SNC, afetando o controle da rede idiotípica e/ou promovendo via FcR a ativação de leucócitos e secreção de quimiocinas ${ }^{10,26}$.

O reconhecimento de que as respostas imunes são fortemente controladas em diversos níveis por genes específicos tem engendrado estudos com o objetivo de estabelecer loci específicos entre susceptibilidade à $\mathrm{EM}^{27,28}$. Uma forte associação suscetibilidade à EM e presença do alelo DQB1*0602 tem sido descrita em diferentes populações étnicas, como caucasianos do norte da Europa, afro-caribenhos e chineses $3,8,29,30$. Contudo, outros alelos como DRB1*0401(DR4) no sul da Itália e nos árabes, DRB1*0301 na Sardenha, DRB1*1501 nos europeus caucasianos e o alelo DRB1*1601 em gregos, romanos e croatas também parecem conferir a suscetibilidade à EM. Os nossos resultados indicam que a resposta imune aos componentes encefalitogênicos da mielina MBP, PLP e sequência MOG92-106 parece não ser influenciada unicamente pela expressão do alelo DQB1*0602, porque não foi observada diferença significativa entre os grupos controle e de pacientes EM. A extensa miscigenação étnica da população brasileira sugere que talvez outros alelos possam estar implicados na resposta autoimune e patogenia da EM.

\section{REFERÊNCIAS}

1. Weiner HL,SelkoeDJ. Inflammation and therapeutic vaccination in CNS diseases. Nature 2002;420:879-884.

2. Noseworthy JH, Lucchinetti C, Rodriguez M, et al. Multiple sclerosis. N Engl J Med 2000;343:938-952.

3. Caballero A, Alves-Leon S, Papais-Alvarenga R, et al. DQB1*0602 confers genetic susceptibility to multiple sclerosis in Afro-Brazilians. Tissue Antigens 1999;54:524-526.

4. Wingerchuk DM, Lucchinetti CF, Noseworthy JH. Multiple sclerosis: current pathophysiological concepts. Lab Invest 2001;81:263.

5. Zipp F, Windermuth $\mathrm{C}$, Pankow $\mathrm{H}$, et al. Multiple sclerosis associated aminoacids of polymorphic regions relevant for HLA binding are confined to HLA-DR2. Hum Immunol 2000;61:1021-1030.
6. Olerup O, Hillert J. HLA class II - associated genetic susceptibility in multiple sclerosis: a critical evaluation. Tissue Antigens 1991;38:1-15.

7. Rezende PA. Aspectos genéticos da esclerose múltipla: I - Estudo em gêmeos. Arq Neuropsiquiatr 1996;54:439-450.

8. Spurkland A, Celius EG, Knutsen I, et al. The HLA - DQ(B1*0102, $B 1 * 0602)$ heterodimer may confer susceptibility to multiplesclerosis in the absence of the HLA - DR (B1*01, B1*1501) heterodimer. Tissue Antigens 1997;50:15-22.

9. Tejada-Simon MV, Hong J, Rivera MV, et al. Reactivity pattern and cytokineprofile of T cells primed by myelin peptides in MS and healthy individuals. Eur J Immunol 2001;31:907-917.

10. Correale J, Bassani MM,Molinas MMB. Oligoclonal bands and antibodies responses in multiple sclerosis. J Neurol 2002;249:375-389.

11. Bernard CCA, John TG, Slavin A, et al. Myelin oligodendrocyte glycoprotein: a novel candidateautoantigen in multiplesclerosis.J Mol Med 1997;75:77-88.

12. Rosbo NK, Ben-Num A. T-cell responses to myelin antigens in MS; relevance of the predominant autoimmune reactivity to myelin oligodendrocyte glycoprotein. J Autoimmun 1998;11:287-299.

13. Krogsgaard $M$, Wucherpfnning KW, Canella $B$, et al. Visualization of myelin basic protein $\mathrm{T}$ cell epitopes in multiple sclerosis lesions using a monoclonal antibody specificfor thehuman histocompatibility leukocyte antigen (HLA)-DR2-MBP 85-99 complex.J Exp Med 2000;191:1395-1412.

14. Poser CM, Paty DN, Scheinberg $L$, et al. New diagnostic criteria for MS: guidelines for research protocols. Ann Neurol 1983;13:227-231.

15. Kurtzke JF. Rating neurological impairment in multiple sclerosis: an expanded disability status scale (EDSS). Neurology 1983;33:1444-1452.

16. Weinshenker BG, Bass B, Rice GPA. The natural history of multiple sclerosis: a geographically based study. I. Clinical courseand disability. Brain 1989;112:133-146.

17. Waksman BH, Porter $\mathrm{H}$, Lees $\mathrm{M}$, et al. A study of the chemical nature of components of bovine white matter effective in producing allergic encephalomyelitis in the rabbit. J Exp Med 1954;451-470.

18. Lees M, Chao BH, Lin LH, et al. A mino acid sequence of bovine white matter proteolipid. Arch Biochem Biophys 1983;226:643-656.

19. Sambrook J, Maniatis T, Fritch EF. Molecular cloning: a laboratory manual. 2.Ed. N ew York: Cold Spring Harbor, 1989:1-9.

20. Olerup O, Aldener A, Fogdell A. HLA - DQB1 and DQA 1 typing by PCR amplification with sequence-specific primers (PCR-SSP) in 2 hours. Tissue Antigens 1993;41:119-134.

21. Al-Omaishi J, Bashir R, Gendelman HE. The cellular immunology of multiple sclerosis. J Leukoc Biol 1999;65:444-452.

22. Lindert R, Haase CG, Brehm U, et al. Multiple sclerosis: B and T-cell responses to the extracellular domain of the myelin oligodendrocyte glycoprotein. Brain 1999;122:2089-2099.

23. Haase CG, Linington C. The fine specificity of myelin oligodendrocyte glycoprotein autoantibody response in patients with multiplesclerosis and normal healthy controls. J N euroimmunol 2001;114:220-225.

24. Linington C, Bradl M, Lassman $\mathrm{H}$, etal. A ugmentation of demyelination in rat acuteallergic encephal omyelitis by circulation mousemonoclonal antibodies directed against a myelin/ oligodendrocyteglycoprotein. Am J Pathol 1988;130:443-454.

25. Kroepfl JF, Viise LR, Charron AJ, et al. Investigation of myelin/ oligodendrocyte glycoprotein membrane topology. J Neurochem 1996;67:2219-2222.

26. Hogarth PM. Fc receptors are major mediators of antiboby based inflammation in autoimmunity. Curr Opin Immunol 2002;14:798-802.

27. Compston DAS, Kellar W, Robertson N, et al. Genes susceptibility to multiple sclerosis. Acta Neurol Scand 1995;161(Suppl):43-51.

28. Pouly S,Antel JA. Multiple sclerosis and central nervous system demyelination. J Autoimmun 1999;13:297-306.

29. Serjeantson SW, Gao X, Hawkins BR, et al. N ovel HLA - DR2 - Related haplotypes in Hong Kong Chinese implicate the DQB1*0602 allele in susceptibility to multiple sclerosis. Eur J Immunogenet 1992;19:11-19.

30. Dekker JW, Easteal S, Gao X, et al. HLA - DPB1 alleles correlate with risk for multiple sclerosis in Caucasoid and Catonese patients lacking the high - risk DQB1*0602 allele. Tissue Antigens 1992;41:31-36. 